\title{
Assessment of droughts in Romania using the Standardized Precipitation Index
}

ARTICLE in NATURAL HAZARDS · JANUARY 2016

Impact Factor: 1.72 · DOI: 10.1007/s11069-015-2141-8

READS

57

3 AUTHORS:

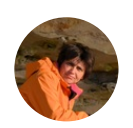

Monica Ionita

Alfred Wegener Institute Helmholtz Centre fo...

40 PUBLICATIONS 153 CITATIONS

SEE PROFILE

\section{Silvia Mihaela Chelcea}

National Institute of Hydrology and Water M...

16 PUBLICATIONS 67 CITATIONS

SEE PROFILE

\section{Patrick Scholz}

Alfred Wegener Institute Helmholtz Centre fo...

13 PUBLICATIONS 24 CITATIONS

SEE PROFILE 
10 Corresponding author:

11 Email: Monica.Ionita@awi.de

12 Address: Alfred Wegener Institute Helmholtz Centre for Polar and Marine Research

13 Bussestrasse 24

14 D-27570 Bremerhaven

15 Telephone: +49(471)4831-1845

16 Fax: +49(471)4831-1271 


\section{Abstract}

This paper analyses the temporal and spatial variability of droughts in Romania, over the last five decades, based on a high-resolution data set developed at country level, namely ROCADA. Droughts are analyzed by means of the Standardized Precipitation Index (SPI) for 3-month, 6month and 12-months time scales.

34 The time period 1979 - 1995 was identified as the period with the highest number of months affected by moderate, severe as well as extreme drought conditions. The $2000-2001$ episode was identified as the major drought event, concerning the severity and the spatial extent, with an area of $60 \%$ of the country affected by extreme drought for more than 10 consecutive months. The results of the trend analysis emphasize an inhomogeneous spatial aspect of the dryness/wetness trends. Statistically significant positive trends (wetter conditions) over small areas distributed inhomogeneous around the country like the southernmost corner as well as the north-eastern part and some small areas in the western part of the country have been identified. Statistically significant negative (drier conditions) trends have been obtained over the southwestern part of the country and over the eastern part. In general, the SPI trends follow the

44 observed trends in the monthly precipitation totals, at country level.

45 The results indicate that there is no spatial consistency in the occurrence of droughts at country 46 level and the SPI at different time scales may vary in its usefulness in drought monitoring, due to 47 the fact that in the case of shorter time scales the SPI values have the tendency to fluctuate 48 frequently above and below the zero line, while for longer time scales there are well defined dry 49 and wet cycles.

Key words: Romania, drought variability, drought trends, Standardized Precipitation 52 Index 


\section{Introduction}

59 Drought is one of the most complex phenomena that can have a strong impact on agriculture, society, water resources and ecosystems. One of the reasons for this is the spatial extent of drought and its duration, sometimes reaching continental scales and lasting for many years. Drought affects many regions of the world and is globally one of the costliest climatic hazards (Wilhite, 2000). Generally, drought originates from a deficiency of precipitation over an extended period of time, usually a season or more. Investigations of drought are carried out all over the world. However, because of the complexity of this phenomenon, a uniform methodology for implementing drought studies has not been developed yet, although some indices of drought are widely used (Dai et al., 2004; Wells et al., 2004; Palmer, 1965). Drought is seen in different ways by different constituency of water users. Drought definitions are of two types: a) conceptual and b) operational (Wilhite, 2000). Conceptual definitions help to understand the meaning of drought and its effects. For example, drought is a prolonged period of deficient precipitation, which causes extensive damage to crops, resulting in loss of yield. These definitions do not provide quantitative answers to "when", "how long", "how severe" a drought is and are often used as a startup in scientific papers and reports. Operational definitions help to identify the drought's beginning, end and degree of severity. To determine the beginning of drought, operational definitions specify the degree of departure from the precipitation average over some time period. This is usually accomplished by comparing the current situation with the historical average. An operational definition for agriculture may compare daily precipitation to evapotranspiration to determine the rate of soil-moisture depletion and express these relationships in terms of drought effects on plant behavior. These definitions are used to analyze drought frequency, severity, and duration for a given historical period. Varied definitions of droughts, depending upon the influential factor, are seen in the literature which can be grouped as follows: a) Precipitation based drought definitions; b) Evapotranspiration based drought definitions; c) Streamflow based drought definitions; d) Soil moisture based drought definitions;

85 Farago et al., 1989; Maracchi, 2000; Dai, 2011). The groups in a) and b) refer to meteorological

86 drought conditions, group c) refers to hydrological droughts and those in d) and e) refer to the 87 agricultural droughts. 
88 Drought propagation depends strongly on climate (Sheffield and Wood, 2011). At European

89 scale, research on drought variability has been mainly focused on regional scales and/or over 90 regions which are exposed to severe droughts [Iberian Peninsula (Estrela et al., 2000; Vicente91 Serrano, 2011); the Mediterranean Region (Livada and Assimakopolous, 2007) and the south92 eastern part of Europe (Koleva and Alexandrov, 2008; Cheval et al., 2014]. Looking at other 93 European regions, Briffa et al. (2009) showed that high summer temperatures in the western and 94 central part of Europe are responsible for the large extent of summer drought conditions. Trnka 95 et al (2009) emphasized that the drought conditions in the central part of Europe are triggered by 96 different atmospheric circulation patterns and that the drought phenomenon is very pronounced 97 in early vegetation period (April - June). Ionita et al. (2012) showed that summer drought 98 conditions over Europe are strongly influenced by previous winter SST anomalies and different 99 ocean and atmospheric modes of variability (e.g. Atlantic Multidecadal Oscillation (AMO), 100 Pacific Decadal Oscillation (PDO) and North Atlantic Oscillation (NAO)). In a recent study, 101 Ionita et al. (2015a) emphasized the combined effect of different teleconnection patterns (e.g. 102 NAO, Arctic Oscillation (AO), East Atlantic (EA)) on the seasonal dryness/wetness variability at 103 European scale.

104 Large areas of Europe have been affected by drought during the $20^{\text {th }}$ century. Severe and 105 prolonged droughts observed mainly in the Mediterranean region have highlighted the 106 vulnerability to this natural hazard and alerted the governments, stake holders, operational 107 agencies to the disastrous effects of droughts on the society and economy and the need for 108 mitigation measures (EEA, 2001). In this context, Romania is very likely to experience a wide 109 range of impacts in response to climate change, mainly due to the temperature increases which in 110 turn can perturb the hydrological cycle. The south, southeast and eastern parts of our country are 111 the most affected areas. During extremely dry years the average yields of various crops 112 represent only $35 \%-60 \%$ of the potential yields. The climate evolution in Romania indicates a 113 diminution of the annual precipitation especially over the south-eastern part of the country 114 (Busuioc et al., 1996).

115 In order to quantify droughts and monitor wet and dry periods, various indices (e.g. SPI; Palmer 116 Drought Severity Index (PDSI); Rainfall Anomaly Index (RAI); Crop Moisture Index (CMI); the 117 Surface Water Supply Index (SWSI), the Standardized Precipitation - Evapotranspiration Index 118 (SPEI)) have been developed (Heim, 2002; Vicente - Serrano et al., 2010), each with its 
weaknesses and strengths (Mishra and Singh, 2010). For characterizing meteorological drought, experts have agreed that the SPI should be used by all National Meteorological and Hydrological Services around the world (WMO, 2012; Hayes et al., 2011). As such, the aim of the current study is to make a country level based assessment of the drought phenomenon, at three different time scales (3,6 and 12 months) over the last 60 years, using the Standardized Precipitation Index.

125 This paper is organized as follow: in section 2 a short introduction about the study area and the 126 data sets used in this study is given. The main results are shown in section 3, while the concluding remarks are given in section 4 .

\section{Study area and data sets}

129 Romania is situated in the southeastern-central part of Europe, north of the Balkan Peninsula and at the western shore of the Black Sea. The climatic conditions are dependent on the country's varied topography (Figure 1). The Carpathians serve as a barrier for the Atlantic air masses, 132 limiting their oceanic influences to the west and center of the country, which experience milder winters and heavier rainfalls as a result. The mountains also block the continental influences of the vast plain to the north in the Ukraine, which results in frosty winters and less rain to the south and southeast. This study is based on monthly precipitation totals data from the ROCADA database (Dumitrescu and Birsan, 2015). ROCADA is a daily gridded observational dataset for precipitation, minimum, mean, maximum temperature, soil surface temperature, sea level pressure, relative humidity, cloud cover and sunshine duration in Romania based on station information. The dataset covers the period 1961 - 2013. It has been developed as part of the EURO4M (EU-FP7) and is now maintained and elaborated for future extensions in space and time as part of the UERRA project (EU-FP7). The data is available on a $0.10^{\circ} \times 0.10^{\circ}$ regular latlon grid. The Multiple Analysis of Series for Homogenization (MASH) v3.03 method and software (Szentimrey 1999, Venema et al. 2012) was used to fill gaps in the data sets, and for quality control and homogenization.

147 with station based observed data, E-OBS data set (Haylock et al., 2008) as well as APHRODITE 148 data set (Yatagi et al., 2012). Based on this comparison, it has been found that ROCADA data set 
149 shares the closest resemblance with observation, when compared with E-OBS and

150 APHRODITE. Moreover, ROCADA data set is better in reproducing the local variability and 151 features for all available variables (e.g. precipitation, temperature, cloud cover, relative 152 humidity). A more detailed explanation regarding the performance of ROCADA is given in 153 Dumitrescu and Birsan (2015).

154 The Standardized Precipitation Index (SPI) is computed following the methodology of McKee et 155 al. (1993) based on the monthly precipitation totals from the ROCADA data set. For this study 156 the SPI is computed for three different accumulation periods: 3-months (SPI3), 6-months (SPI6) 157 and 12-months (SPI12). The data set is fitted to a gamma probability distribution and then 158 normalized to a standard normal probability distribution (e.g. the mean SPI is 0 and its standard 159 deviation is 1). For a normally distributed random variable, the index is basically the number of 160 standard deviations by which the observed value lies above or below the long-term means. The 161 present study focuses on moderate (SPI3), severe (SPI6) and extreme drought (SPI12). A 162 detailed description of the SPI calculation can be found in McKee et al. (1993) and Hayes et al. 163 (1999).

164 In order to analyze the temporal structure (interannual and decadal variability) of the monthly 165 SPI3, SPI6 and SPI12 variability at country level, we have applied the wavelet power spectrum 166 analysis. The wavelet analysis used in this paper follows the methods of Torrence and Compo 167 (1998). Statistical significance is determined against a red noise null hypothesis using a chisquared test. By decomposing a time series into a time-frequency space, it is possible to determine the dominant modes of variability, as well as, how these modes vary in time. The wavelet transform is designed to analyze time series that contain non-stationary power over many different frequency scales (Daubechies, 1990). The wavelet transform breaks up a signal into scaled versions of a wavelet function, where the scale of the wavelet (the window) varies with frequency. Thus, the wavelet is narrow in time at high frequencies and the scale of the wavelet increases with decreasing frequency. The wavelet transform expresses a time series in a three-dimensional space: time (x), scale/frequency (y), and power (z). 


\section{Results}

\subsection{Temporal evolution of drought indices at country level}

182

The key feature of SPI is that it can be used to quantify the precipitation deficit for varying time scales. These time scales (e.g. 3, 6, 12 months) reflect the impact of the drought on the availability of different water resources. A 3-month SPI reflects short and medium soil moisture conditions, while the 6-month SPI can effectively represent precipitation anomalies over distinct seasons and indicate medium-range trend in precipitation. The 12-month SPI reflects the longterm precipitation trends (Edossa et al., 2010).

The time series of the monthly values of the 3-month, 6-month and 12-month SPI, averaged at country level, together with their wavelet spectrum are presented in Figure 2. At country level, the most severe and prolonged drought occurred from 1982 until 1996 (Figure 2a, c, and e). This prolonged dry period is very well captured by the monthly time series of SPI6 (Figure 2c) and the monthly time series of SPI12 (Figure 2e). At short time scales (e.g. SPI3) SPI shows a higher frequency of change between dry and wet periods (Figure 2a). With increasing time scales, the variation between dry and wet periods shows a lower frequency of change and a longer duration (Figure 2c). At shorter time scales SPI has the tendency to fluctuate frequently above and below the zero line, while for longer SPI time scales there are well defined wet and dry cycles, especially the dry period from 1982 up to 1996, and the two wet periods from 1965 up to 1982 and 2005 up to 2011, respectively. Similar results, namely prolonged dry period from 1982 until 1996, have been obtained when looking at the drought conditions averaged over the entire Danube river catchment area (Ionita et al., 2015b). As can be inferred from Figure 2a, c and d, very dry periods, alternate with wet periods, but there is no obvious trend for the three SPI time scales analyzed.

To examine the spectral characteristics of drought index at different time periods, a Morlet wavelet analysis (Torrence and Compo, 1998; Grinsted et al., 2004) was performed on the SPI time series and the results are shown in Figure $2 b, d$ and $f$, respectively. The power spectrum produced for the SPI time series is the product of the natural processes involved and noise. The black contour lines in Figure 2b, $\mathrm{d}$ and $\mathrm{f}$ indicate peaks greater than 95\% confidence level against a red noise process. It has to be mentioned that the regions of the power spectrum which are out of the $90 \%$ confidence level are not necessarily the product of noise only. Natural processes are 
210 present also outside the $95 \%$ confidence level, but influence the power spectrum to a lesser 211 extent. Observed multi-year fluctuations in Figure 2b, d and f (1 - 2 years, 2 -4 years) correspond 212 to well known energy bands that characterize some climate indices affecting the European 213 climate and more generally the global climate, such as the North Atlantic Oscillation (NAO), a 214 phenomena which is recognized as a major forcing climatic factor of the European streamflow, 215 precipitation and temperature (Rimbu et al., 2005, Cullen et al, 2002, Trigo et al., 2004). For 216 SPI3 (Figure 2b), the power is broadly distributed in the $0.5-2$ years band. The $95 \%$ confidence 217 region demonstrates that the periods $1965-1975$ and $2000-2005$ are characterized by higher 218 variance (Figure 2b). Outside these periods there are no significant bands characteristic to short 219 term drought conditions. For the mid-term drought conditions (SPI6) the power is distributed 220 mostly in $1-3$ years band (Figure 2d). As in the case of SPI3, the spectral characteristic of SPI6 shows epochal variations. The highest variance, significant at 95\% confidence level, was recorded from 1962 up to 1980, from 1987 up to 1993 and from 1996 up to 2005. Comparing to SPI3, the spectral characteristics obtained for SPI6 are more stable (longer time periods are characterized by the same spectral characteristics). For the longer duration drought (SPI12) the spectral analysis indicates a concentration of power in the $1-4$ years band. This energy band is visible over almost entire analyzed period, with some small exceptions over the period 1978 1985. Outside the significant energy bands mentioned before, all three SPI time series (SPI3, SPI6 and SPI12) show also multidecadal variability, especially in the $10-16$ years band. As stated before, natural processes could be present also outside the 95\% confidence level. Similar decadal component has been found in the spectral characteristics of the European droughts (Ionita et al., 2012), the Romanian streamflow (Ionita et al., 2014) and of the monsoon droughts over India (Kumar et al., 2013).

235 To provide a complete picture of the hot spots, at country level, over the last five decades, we split the data set in three different time periods (17 years): 1962 - 1978, 1979 - 1995 and $1996-$ 2013, respectively. We choose these periods to have an equal number of month/years (204/17) for all the analyzed periods. The aim of splitting the data in three different time periods was to test if there were significant changes in the drought conditions between the different periods. The analysis is performed for SPI3, SPI6 and SPI12 for three different drought categories (McKee et 
al., 1993): moderate $(-1.5<\mathrm{SPI} \leq-1.0)$, severe $(-2.0<\mathrm{SPI} \leq-1.5)$ and extreme $(\mathrm{SPI} \leq-2.0)$. The frequency in each category (moderate - Figure 3, severe - Figure 4 and extreme - Figure 5) is expressed as the number of months/time period in a given category when SPI3, SPI6 and SPI12 was below a certain threshold (see the definition of the thresholds in the caption figure of Figures 3, 4 and 5).

During the 1962 - 1978 period the drought hot spots, in terms of moderate drought conditions, are homogenous distributed at country level (Figure 3a, b and c). In the case of SPI12 (Figure 3c) a higher number of months, affected by moderate drought, can be observed in the north-western part of the country. For the period 1979 - 1995 there is an obvious increase in the number of months affected by moderate drought, compared to the period 1962 -1978 (Figure 3e, e and f). Especially for SPI6 (Figure 3e) and SPI12 (Figure 3f), there is a much higher frequency of moderate drought events over the southern part of the country. This particular dry period was identified also in Figure 2, for the monthly time series of SPI3, SPI6 and SPI12 average at country level. For the last analyzed period $(1996$ - 2013) there is a decrease in the number of months characterized by moderate drought, compared to the period 1978 - 1995 (Figure $3 \mathrm{~g}, \mathrm{~h}$ and i). There are no significant differences between the three different SPI time scales and the drought conditions are homogenous distributed all over the country. In terms of severe drought (Figure 4), the period $1962-1978$ is characterized by a smaller number of months which are affected by severe droughts compared to the same period, but for moderate droughts. For SPI3 (Figure 4a) and SPI6 (figure 4b) there is a similar distribution in the number of months characterized by severe drought, while for SPI12 (Figure 4c) there are just few regions, where severe droughts were recorded over this period of time, like: the northwestern and north-eastern parts of Romania. For the period $1979-1995$, as in the case of the moderate drought, there is an obvious increase in the number of months characterized by severe drought, for all the three SPI time scales (Figure 4d, e and f). The highest number of months, characterized by severe droughts is recorded for SPI 12 (Figure 4f). The most affected areas by severe drought, over the period 1979 - 1995, are the southern, southwestern and central parts of the country, where there are up to 45 months (out of 204 months) that were affected by severe drought. For the last analyzed period (1996 - 2013) there is a decrease in the number of months characterized by severe drought, as in the case of moderate drought, compared to the period 1978 - 1995 (Figure $4 \mathrm{~g}, \mathrm{~h}$ and i). There are no significant differences between SPI3 (Figure 4g) and 
272 SPI6 (Figure 4h) time scales, the severe drought conditions are distributed all over the country, 273 except some small part form the eastern part of the country, where no severe drought was recorded for this period. In the case of SPI12 (Figure 4i) there are just small areas that were

275 affected by severe drought, especially in the north-western part of the country.

276 In Figure 5, the hot spots regarding the extreme drought are shown. For the period $1962-1978$

277 (Figure 5a, b and c) there are relatively just few months (up to 10/period) when extreme drought 278 conditions were recorded, mostly over the eastern part of the country for SPI3 (Figure 5a) and 279 SPI6 (Figure 5b). In the case of SPI12 (Figure 5c), extreme droughts were recorded just over the north-eastern part of the country. As in the case of the moderate and severe drought, the period 1979 - 1995 is characterized by an increased number of months characterized by severe drought. For SPI3 (Figure 5d) and SPI6 (Figure 5e) the most affected area by severe droughts were located in the south and north-eastern part of the country. For SPI12 (Figure 5f) the number of months characterized by extreme drought is much higher compare to SPI3 and SPI6, respectively. The most affected areas are the southern part, the central part and the north-eastern part of the country. As in the case of moderate and extreme drought, for the last period analyzed (1996 - 2013), the drought conditions were very sparse and the number of months affected by drought was rather small, in the case of extreme drought, the last period analyzed, has quite opposite features (Figure 5g, h and i). For SPI3 (Figure 5g), SPI6 (Figure 5h) and SPI12 (Figure 5i) the western part of the country is characterized by a high number of months which are affected by extreme drought conditions. In contrast to this, the eastern part is free of extreme drought conditions during the last analyzed period.

\subsection{Identification of drought events}

294 Romania has experienced a number of dry periods within the last five decades that have been documented in previous studies (Cheval et al., 2014; Stefan et al., 2008). Figure 6 provides a view of such periods by plotting the percentage area affected by three different classes of drought: moderate $(-1.5<\mathrm{SPI} \leq-1.0)$, severe $(-2.0<\mathrm{SPI} \leq-1.5)$ and extreme $(\mathrm{SPI} \leq-2.0)$ considering the 3-month (Figure 6a), 6-month (Figure 6b) and 12-month (Figure 6c) SPI indices. In agreement with the temporal evolution of the monthly time series of SPI3 (Figure 2a), SPI6 (Figure 2b) and SPI12 (Figure2c) there are altering periods of intense dryness and wetness, with a coverage of almost $60 \%$ characterized by prolonged drought conditions and periods of no drought or reduced drought in term of spatial coverage. The driest years, in terms of spatial 
303

304

305

306

307

308

309

310

311

312

313

314

315

316

317

318

319

320

321

322

323

324

325

326

327

328

329

330

331

332

coverage are: 1965 - 1966, 1974, 1986, 2000, 2002, 2003 and 2011. For all the aforementioned years there were at least 3 consecutive months when the total area covered by extreme drought, for SPI3, SPI6 and SPI12, was above 30\%. The years 2000/2001 stand out as the driest years, the area covered by drought being almost $60 \%$ for moderate, severe and extreme drought. This can be also observed when looking at the spatial distribution of SPI3 (Figure 7a), SPI6 (Figure 7b) and SPI12 (Figure 7c) averaged over May 2000 up to February 2001. For these particular months and for almost the entire country, the recorded values of SPI3, SPI6 and SPI12 were $\leq-2$ (Figure 7). The most affected areas were the southern, central and north-western part of the country.

\subsection{Trend analysis}

The spatial distribution of the monthly SPI trends is shown in Figure 8. Positive and negative trends, which represent trends toward wetter and drier conditions, were detected. The trends were investigated using the non-parametric Spearman's Rho test and the 95\% confidence level (Wilks, 2006). The trend analysis (values/period 1962 - 2013) was performed for SPI3, SPI6 and SPI12 indices as well as for the monthly precipitation totals at country level. Figure 8 shows that drying trends (statistically significant at $95 \%$ confidence level) are located over the south-western and the eastern most part of the country, as well as some small areas in the western and northern part of the country. The trend observed for SPI3 (Figure 8a), SPI6 (Figure 8b) and SPI12 (Figure 8c) are similar and they follow the trend observed in the precipitation totals at country level (Figure 8d). Over the north-western and north-eastern part of the country, as well as the south-eastern most corner of the country there are positive (wetting) and significant trends for all the SPI indices as well as for the precipitation totals. The inhomogeneous spatial distribution of the trends indicates that dryness/wetness conditions can be highly diverse spatially, with some areas being affected by severe drought, while other areas being affected by moderate or no drought at all.

\section{Conclusions}

SPI is a valuable index for assessing the variability of dryness/wetness conditions due to its capacity to represent precipitation anomalies. SPI is used for operational and research activities in more than 70 countries around the world (WMO, 2012). As such, in this study we assessed the 
333 frequency and the spatial coverage of droughts in Romania, over the period 1962 - 2013, using 334 high-resolution data sets of precipitation totals developed at country level (Dumitrescu and Birsan, 2015). Droughts, at country level, were assessed using the SPI for three different time scales: 3-month, 6-month and 12-months, respectively. The 2000 - 2001 drought episode, which has produced major socio-economic damages and is considered the most intense and devastating drought event in the last 60 years at country level (Croitoru et al., 2011) was identified by SPI3, SPI6 and SPI12 as the major drought event in terms of duration and spatial extent.

In terms of frequency, the period $1979-1995$ was identified as the period with the highest number of months affected by moderate, severe as well as extreme drought. This feature is very well emphasized for the longer time scales of SPI (e.g. SPI12, see Figures 3i, 4i and 5i). In the case of shorter time scales, the SPI values have the tendency to fluctuate frequently above and below the zero line (see Figure 2a), while for longer time scales there are well defined dry and wet cycles (see Figure 2c). These findings highlight the need for a comprehensive consideration of different time scales when SPI is employed in drought monitoring. The results of the trend analysis emphasized an inhomogeneous spatial aspect of the dryness/wetness trends. There are statistically significant (95\% confidence level) positive trends (wetter conditions) over small areas distributed inhomogeneous around the country like the southernmost corner as well as the north-eastern part and some small areas in the western part of the country. Negative (drier conditions) significant trends (95\% confidence level) have been obtained over the south-western part of the country and over the eastern part. In general, the SPI trends follow the observed trends in the monthly precipitation totals, at country level. This inhomogeneous pattern in drought trends was identified also by other studies (Cheval et al., 2014 and Paltineanu et al., 2009). Cheval et al. (2014) showed that there is no spatial consistency in the seasonal drought frequency, magnitude or intensity among different regions of the country. Since the southern part of Europe, including Romania, are considered more and more vulnerable to different kinds of droughts (e.g. meteorological, hydrological and pedological) (IPCC, 2014) and due to the fact the drought have a high impact on the socio - economic sector, it's necessary to assess the future of drought severity and magnitude. The results of this study suggest that water resources management strategies should be adjusted according to the changing trends in precipitation and the spatial extent of drought frequency. Further analysis will be developed for 
363 various climate change scenarios and models to better estimate the impacts of climate changes on 364 drought variability and tendencies over Romania. 
384 Compliance with Ethical Standards.

385 Funding: M. Ionita was supported by the REKLIM (Regionale Klimaänderungen/Regional 386 Climate Change) Project.

387 Conflict of Interest: The authors declare that they have no conflict of interest.

388 Ethical approval: This article does not contain any studies with human participants or animals 389 performed by any of the authors.

390 Informed consent: Informed consent was obtained from all individual participants included in 391 the study.

392

393

394

395

396

397

398

399

400

401

402

403

404

405

406

407

408

409

410

411

412

413

414

415

416

417

418

419

420

421

422

423

424

425

426

427

428

429 


\section{References}

Briffa KR, van der Schrier G, Jones PD (2009) Wet and dry summers in Europe since 1750: evidence of increasing drought. Int J Climatology 29:1894-190.

Busuioc A, and von Storch H (1996) Changes in the winter precipitation in Romania and its relation to the large-scale circulation. Tellus 48A:538-552.

Cheval S, Busuioc A, Dumitrescu A, Birsan MV (2014) Spatio-temporal variability of meteorological drought in Romania using the standardized precipitation index (SPI). Clim Res 60:235-248.

Croitoru AE, Toma FM, Dragota C (2011) Meteorological drought in central Romanian Plain (between Olt and Arges rivers). Case study: Year 2000. Riscuri si catastrofe, Vol. 9, nr. 1.

Cullen, H.M., Kaplan, A., Arkin, P. and DeMenocal, P.B. 2002. Impact of the North Atlantic Oscillation on Middle Eastern climate and streamflow. Clim. Change, 55, 315-338.

Dai A, Trenberth KE, Qian T (2004) A global dataset of Palmer drought severity index for 1870-

Dai A (2011) Characteristics and trends in various forms of the Palmer Drought Severity Index during 1900-2008. Journal of Geophysical Research, 116, D12115, doi:10.1029/2010JD015541. 2002: Relationship with soil moisture and effects of surface warming. Journal of Hydrometeorology, 5, 1117- 1130 .

Daubechies I (1990) The wavelet transform, time-frequency localization and signal analysis. IEEE Trans. Information Theory 36: 965 - 1005.

Dumitrescu A, and Birsan VM (2015) ROCADA: a gridded daily climatic dataset over Romania (1961-2013) for nine meteorological variables. Natural Hazards, vol. 78 (2), pp 10451063.

Edossa D, Babel M, Das Gupta A (2010) Drought analysis in the Awash River Basin, Ethiopia. Water Resour Manage 24(7):1441-1460. doi:10.1007/s11269-009-9508-0.

EEA (European Environmental Agency) (2001) Sustainable water use in Europe. Part 3: Extreme hydrological events: floods and droughts. Environmental Issue Report No. 21.

Estrela MJ, Penarrocha D, Millan M (2000) Multi-annual drought episodes in the Mediterranean (Valencia region) from 1950-1996. A spatio-temporal analysis. Int J Climatol 20:15991618. 
Farago T, Kozma E, Nemes C (1989) Drought indices in meteorology. Idojaras, 93(1), 45-59. Hayes MJ, Svoboda MD, Wall N, Widhalm M (2011) The Lincoln declaration on drought indices: universal meteorological drought index recommended. Bull Am Meteorol Soc 92:485-488.

Haylock MR, Hofstra N, Klein Tank AMG, Klok EJ, Jones PD, New M (2008) A European daily high-resolution gridded dataset of surface temperature and precipitation. J Geophys Res (Atmos)113:D20119. doi:10.1029/2008JD10201

Heim R (2002) A review of twentieth-century drought indices used in the United States. Bull Am Meteorol Soc 83:1149-1165.

Ionita M, Lohmann G, Rimbu N, Chelcea S, Dima M (2012) Interannual to decadal summer drought variability over Europe and its relationship to global sea surface temperature. Clim Dyn 38(1-2):363-377.

Ionita, M., S. Chelcea, N. Rimbu and M-J Adler, 2014: Spatial and temporal variability of winter streamflow over Romania and its relationship to large-scale atmospheric circulation. Journal of Hydrology, 519 (B): 1339-1349. DOI: 10.1016/j.jhydrol.2014.09.024

Ionita M, Boroneant C, Chelcea S (2015a) Seasonal modes of dryness and wetness variability over Europe and their connections with large scale atmospheric circulation and global sea surface temperature. Climate Dynamics, in press, DOI: 10.1007/s00382-015-2508-2.

Ionita M, Chelcea S, Scholz P (2015b) Spatio-temporal variability in dryness/wetness in the Danube River Basin. Submitted to Hydrological Processes.

IPCC (2014) Climate Change 2014: Impacts, Adaptation, and Vulnerability. Part A: Global and Sectoral Aspects. Contribution of Working Group II to the Fifth Assessment Report of the Intergovernmental Panel on Climate Change [Field, C.B., V.R. Barros, D.J. Dokken, K.J. Mach, M.D. Mastrandrea, T.E. Bilir, M. Chatterjee, K.L. Ebi, Y.O. Estrada, R.C. Genova, B. Girma, E.S. Kissel, A.N. Levy, S. MacCracken, P.R. Mastrandrea, and L.L. White (eds.)]. Cambridge University Press, Cambridge, United Kingdom and New York, NY, USA, $1132 \mathrm{pp}$.

Koleva E, Alexandrov V (2008) Drought in the Bulgarian low regions during the 20th century. Theor Appl Climatol 92:113-120. 
Kumar K.N., M. Rajeevan, D.S. Pai, A.K. Srivastava, B. Preethi (2013) On the observed variability of monsoon droughts over India. Weather and Climate Extremes, Vol.1, pp $\underline{42-50 .}$

Livada I, Assimakopoulos VD (2007) Spatial and temporal analysis of drought in Greece using the Standardized Precipitation Index (SPI). Theor Appl Climatol 89:143-153.

Maracchi G (2000) Agricultural drought - a practical approach to definition, assessment and mitigation strategies. In: Vogt, J. V., Somma, F. (eds) Drought and drought mitigation in Europe. Advances in Natural and Technological Hazards Research, vol. 14, Kluwer Academic Publishers, 63-75.

McKee, TBN, Doesken J, Kleist J (1993) The relationship of drought frequency and duration to time scales. In Proceedings Eight Conference on Applied Climatology, Anaheim, CA, American Meteor Society, 179-184.

Mishra AK, Singh VP (2010) A review of drought concepts. J Hydrol 391:202-216.

Palmer WC (1965) Meteorological Drought. Res. Paper No. 45: Weather Bureau Washington D.C., $58 \mathrm{pp}$.

Sheffield J, and Wood EF (2011) Drought: Past Problems and Future Scenarios, Earthscan, UK, pp 192.

Stefan S, Ghioca M, Rimbu N, Boroneant C (2004) Study of meteorological and hydrological drought in southern Romania from observational data. Int. J. Climatol. 24: 871-881. doi: 10.1002/joc.1039. 
518

519

520

521

522

523

524

525

526

527

528

529

530

531

532

533

534

535

536

537

538

539

540

541

542

543

544

545

546

547

Szentimrey T (1999) Multiple Analysis of Series for Homogenization (MASH). Proceedings of the 2nd Seminar for Homogenization of Surface Climatological Data. Budapest, Hungary. WMO, WCDMP-No. 41: 27-46.

Torrence C, and GP Compo (1998) A Practical Guide to Wavelet Analysis. Bull. Amer. Meteor. Soc., 79, 61-78.

Trigo, R.M., D. Pozo-Vázquez, T.J. Osborn, Y. Castro-Diez, S. Gamiz-Fortis, and M.J. EstebanParra, 2004: North Atlantic Oscillation influence on precipitation, river flow and water resources in the Iberian Peninsula. Int. J. Climatol., 24, 925-944.

Trnka M, Kysely J, Možný M, Dubrovský M (2009a) Changes in Central-European soilmoisture availability and circulation patterns in 1881-2005. Int J Climatol 29(5):655672.

Venema VKC, Mestre O, Aguilar E, Auer I, Guijarro JA, Domonkos P, Vertacnik G, Szentimrey T, Stepanek P, Zahradnicek P, Viarre J, Muller-Westermeier G, Lakatos M, Williams CN, Menne M, Lindau R, Rasol D, Rustemeier E, Kolokythas K, Marinova T, Andresen L, Acquaotta F, Fratianni S, Cheval S, Klancar M, Brunetti M, Gruber C, Prohom Duran M, Likso T, Esteban P, Brandsma T (2012) Benchmarking homogenization algorithms for monthly data. Climate of the Past 8: 89-115. doi: 10.5194/cp-8-89-2012.

Vicente-Serrano SM, Beguería S, López-Moreno JI (2010) A multi-scalar drought index sensitive to global warming: the Standardized Precipitation Evapotranspiration IndexSPEI. J Clim 23(7):1696-1718.

Vicente-Serrano SM, López-Moreno JI, Drumond A, Gimeno L and others (2011) Effects of warming processes on droughts and water resources in the NW Iberian Peninsula (1930-2006). Clim Res 48:203-212.

Wells N, Goddard S, and Hayes MJ (2004) A self-calibrating Palmer Drought Severity Index. Journal of Climate, 17, 2335-2351.

Wilhite DA, and Glantz MH (1985) Understanding the drought phenomenon: the role of definitions. Water International, 10, 111-120.

Wilhite DA (Ed.) (2000) Drought: A Global Assessment (2 volumes, 51 chapters, 700 pages). Hazards and Disasters: A Series of Definitive Major Works (7-volume series), edited by A.Z. Keller: Routledge Publishers, London, U.K. 
548 Wilks DS (2006) Statistical Methods in the Atmospheric Sciences. 2d ed. International $549 \quad$ Geophysics Series, Vol. 91, Academic Press, 627 pp.

550 WMO (2012) Standardized Precipitation Index (M. Svoboda, M. Hayes and D. Wood). User 551 guide. WMO-1090, Geneva.

552 World Meteorological Organization (WMO) (1975) Drought and agriculture. WMO/TN, 138, 553 Geneva, 118 pp.

554 Yatagai A, Kamiguchi K, Arakawa O, Hamada A, Yasutomi N, Kitoh A (2012) APHRODITE: 555 constructing a long-term daily gridded precipitation dataset for Asia based on a dense 556 network of rain gauges. B Am Meteorol Soc 93:1401-1415. doi: 10.1175/BAMS-D-11-

$557 \quad 00122.1$

558

559

560

561 


\section{Drought Romania}

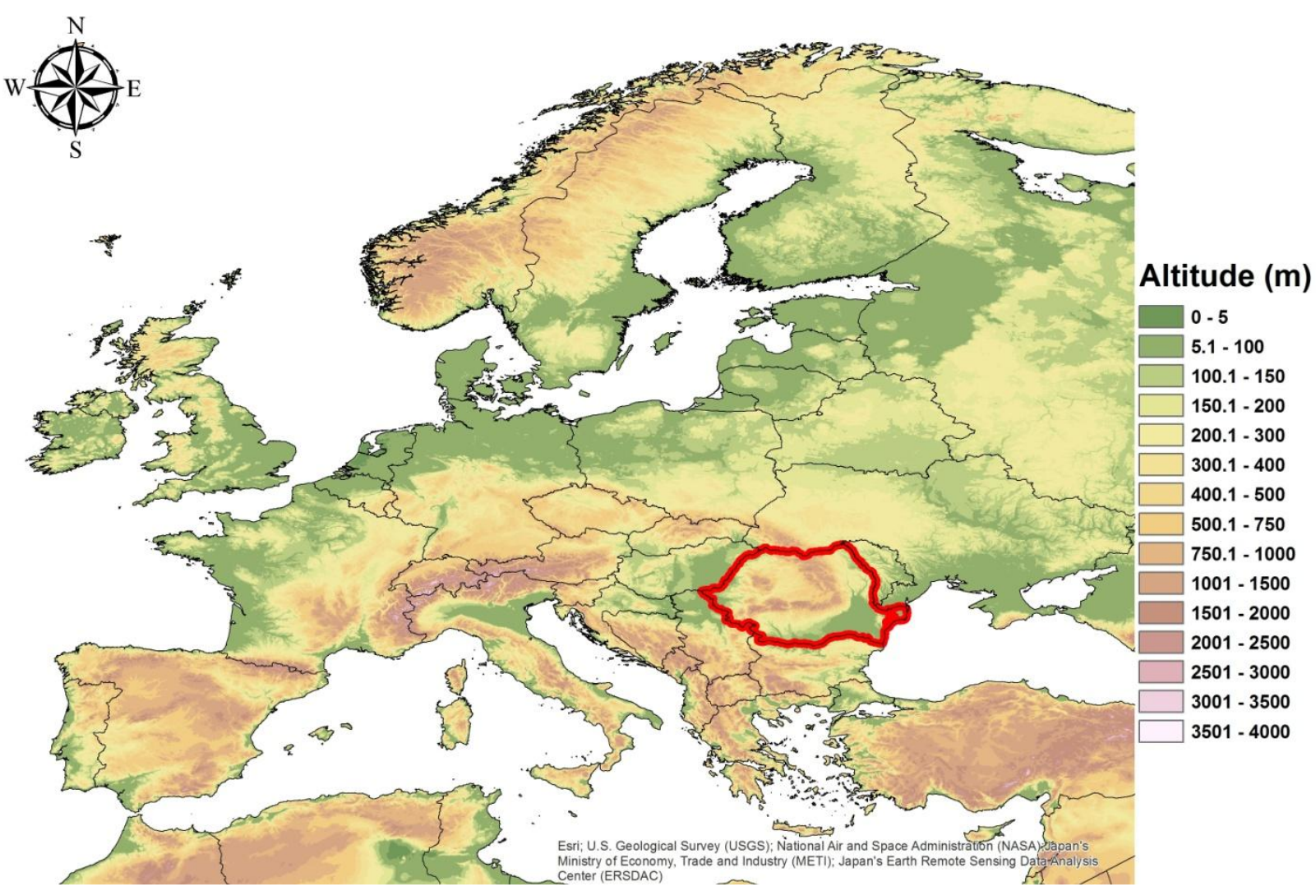

Figure 1. The topographic map of Europe and the location of Romania (red contour). 


\section{Drought Romania}

(a)

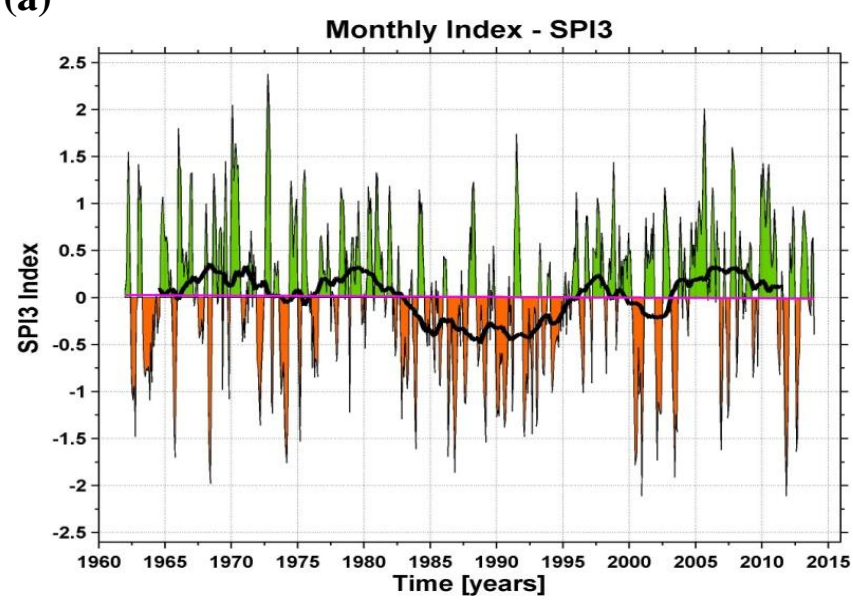

(c)

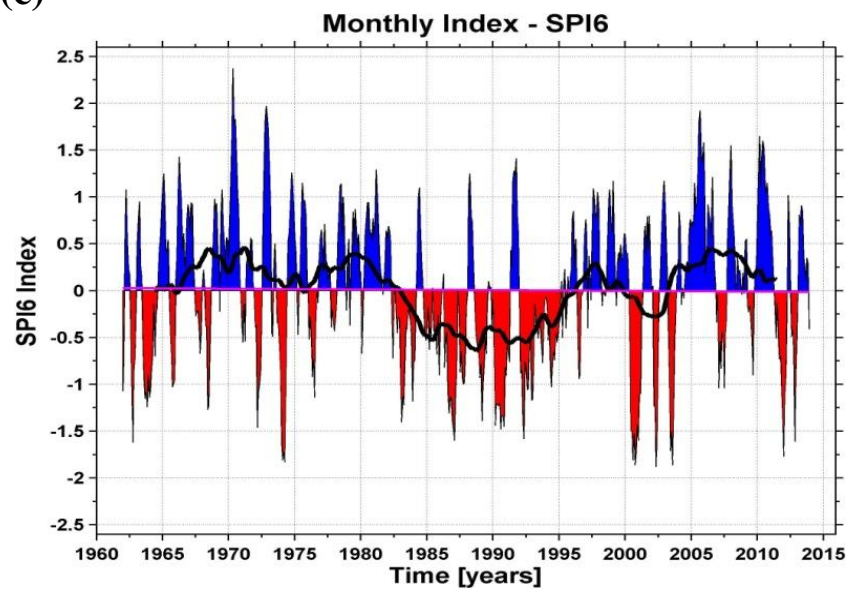

(e)

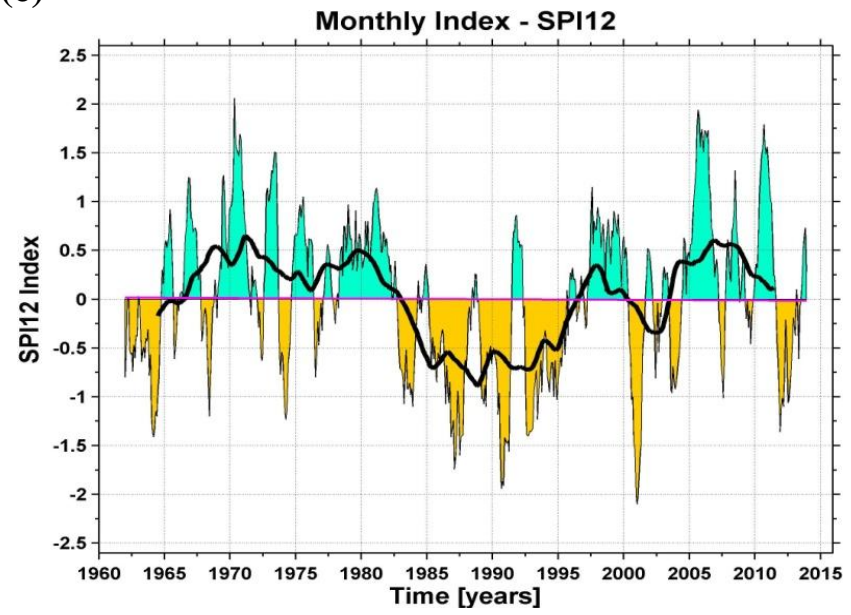

(b)

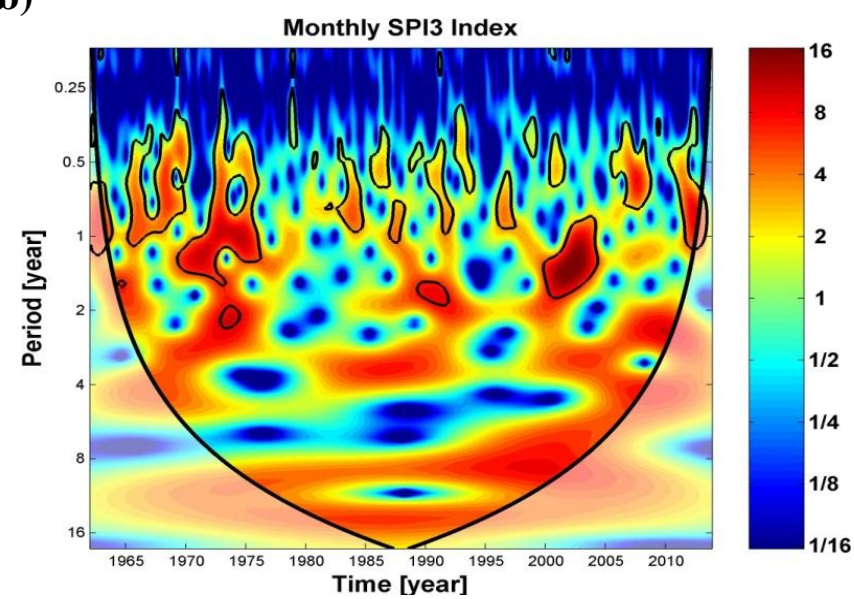

(d)

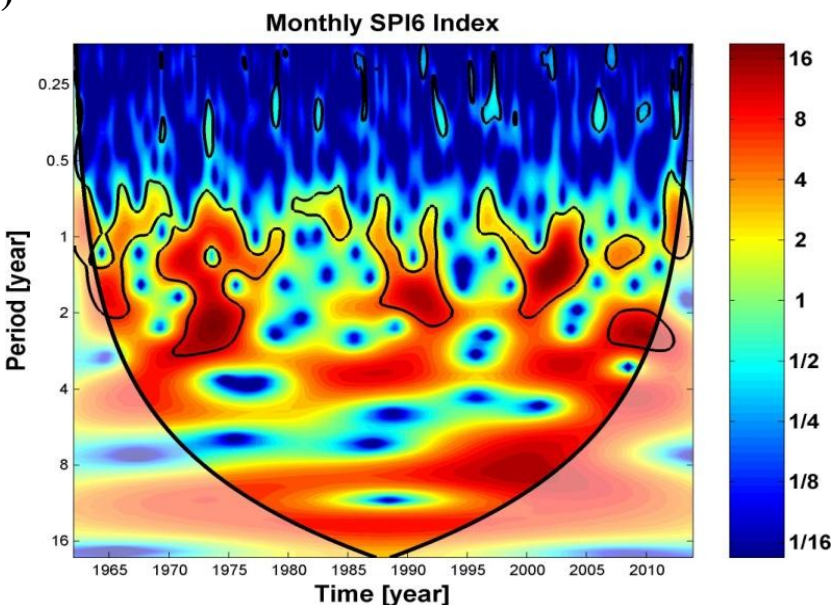

(f)

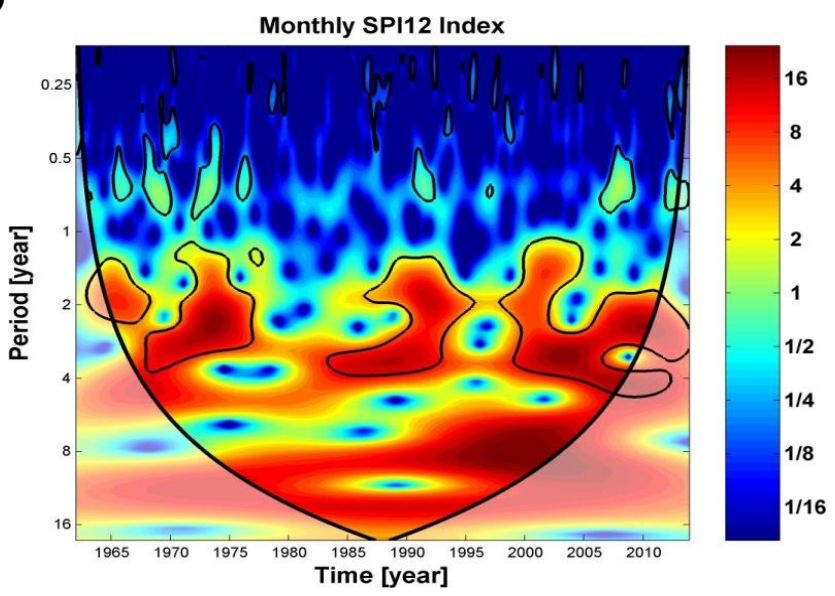

Figure 2. (a) The times series of monthly values of SPI3 index (1962 - 2013) averaged at country level;

(b) The continuous wavelet power spectrum of the time series of SPI3;

(c) As in (a) but for SPI6; (d) As in (b), but for SPI6;

(e) As in (a), but for SPI12; (f) As in (b), but for SPI12;

The thick black contour in (b), (c) and (d) represents the 5\% significance level against red noise.

Colors show the power (or variance). 
(a)

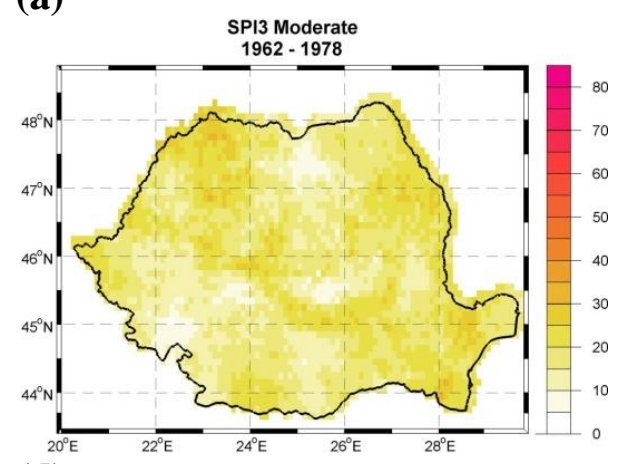

(d)

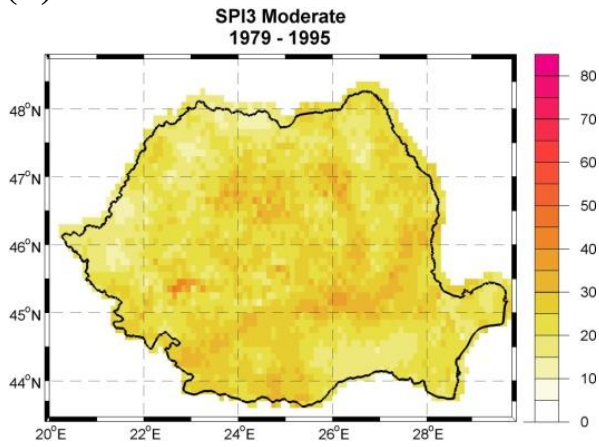

(g)

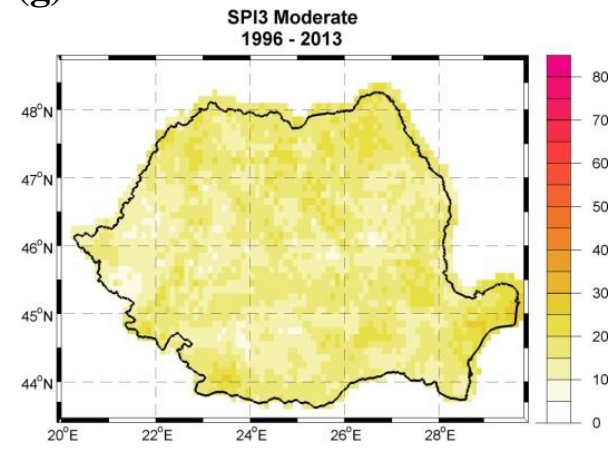

(b)

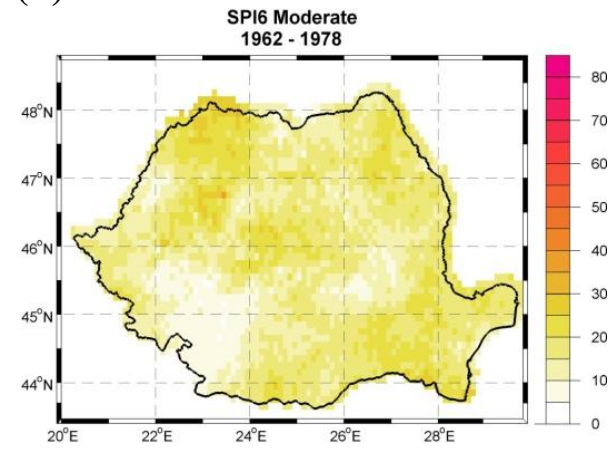

(e)

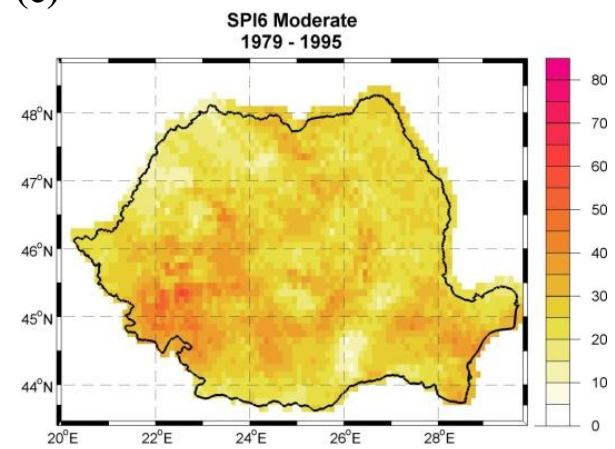

(h)

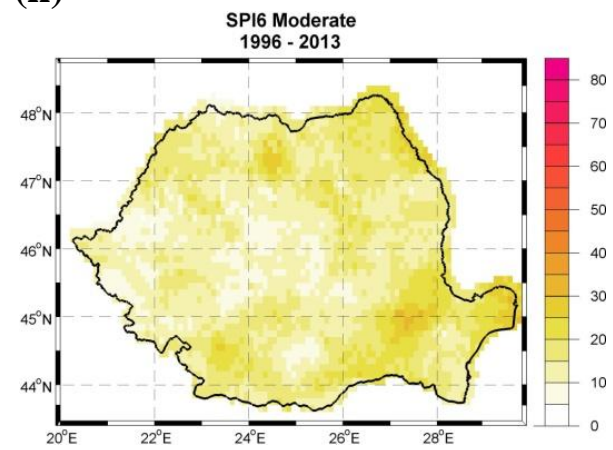

(c)

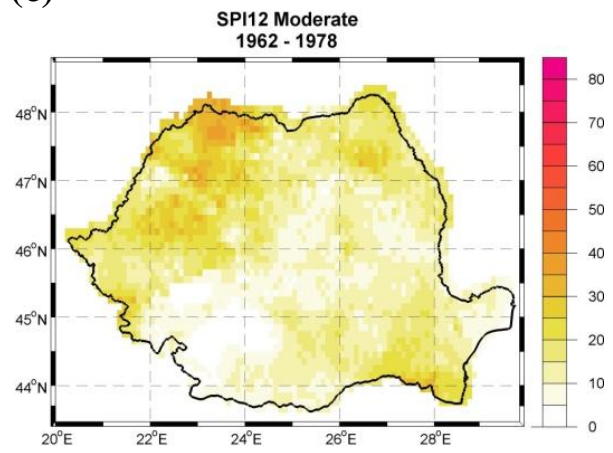

(f)

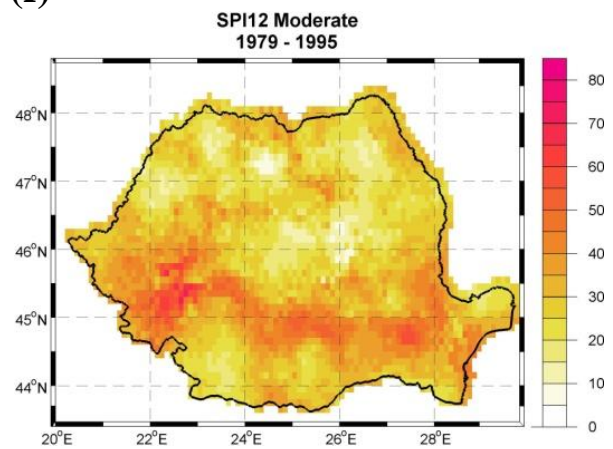

(i)

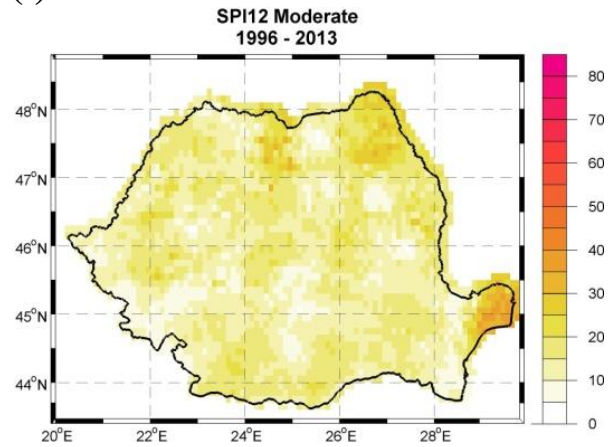

Figure 3. Total moderate drought $(-1.5<\mathrm{SPI} \leq-1)$ duration maps over different periods of time [1962 - 1978 (first row), 1979 - 1995 (second row) and 1996 - 2013 (third row)] and for three different SPI times scales [SPI3 (first colum), SPI6 (second column) and SPI12 (third column)].

Units: number of months/period. 
(a)

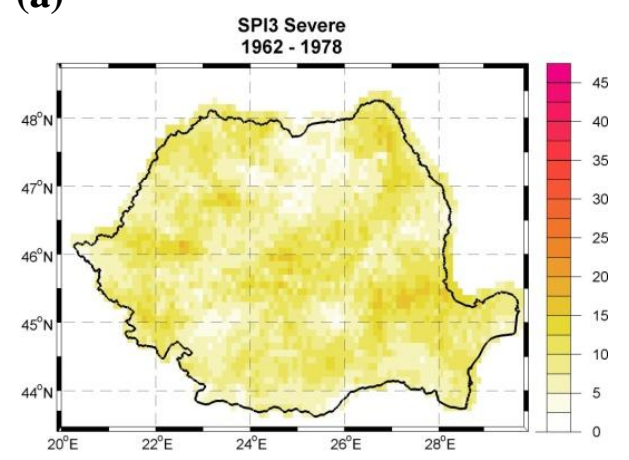

(d)

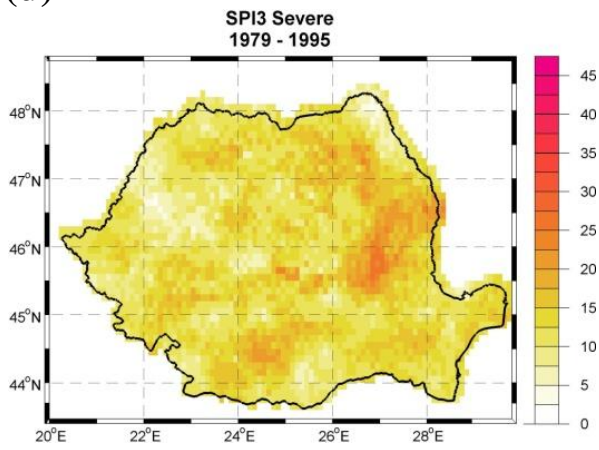

(g)

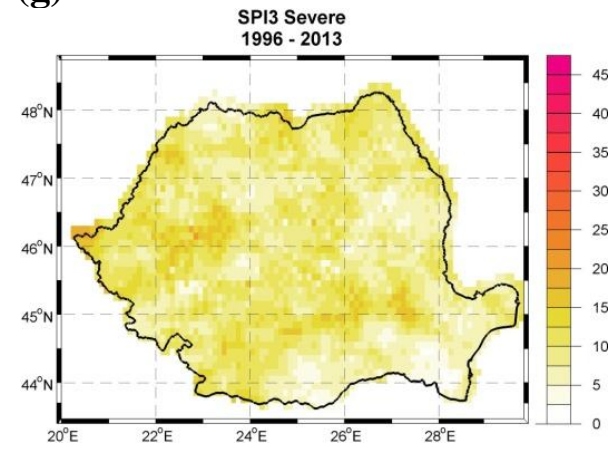

(b)

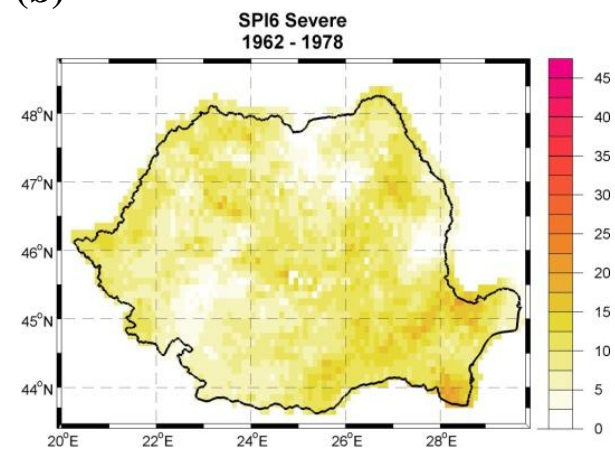

(e)

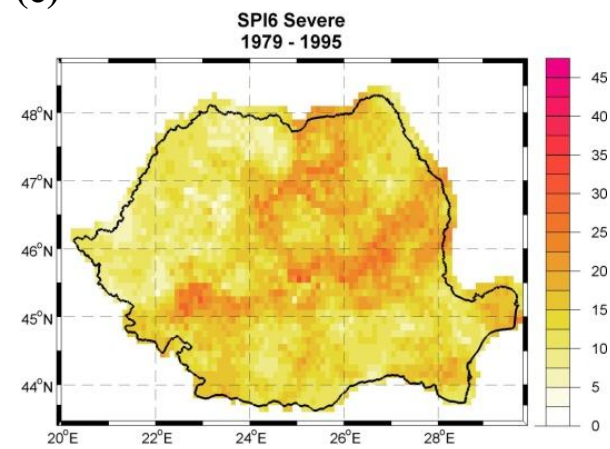

(h)

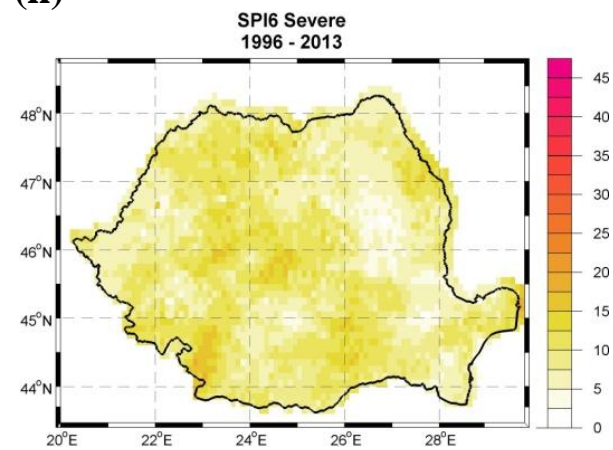

(c)

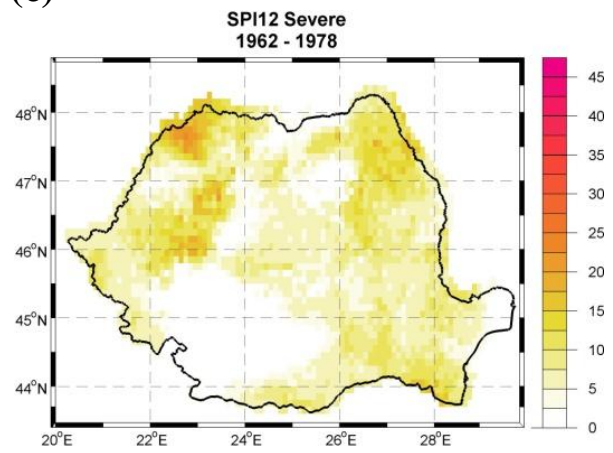

(f)

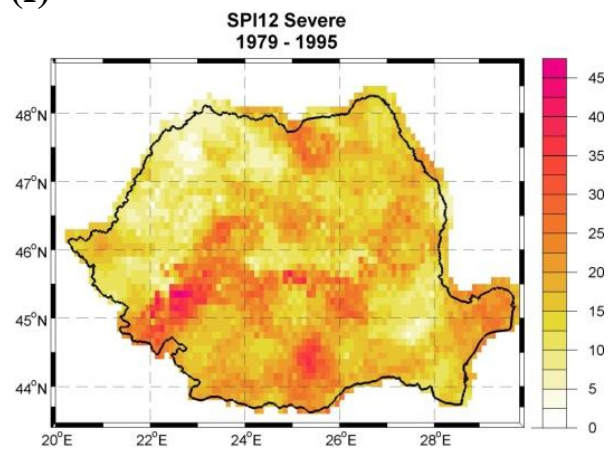

(i)

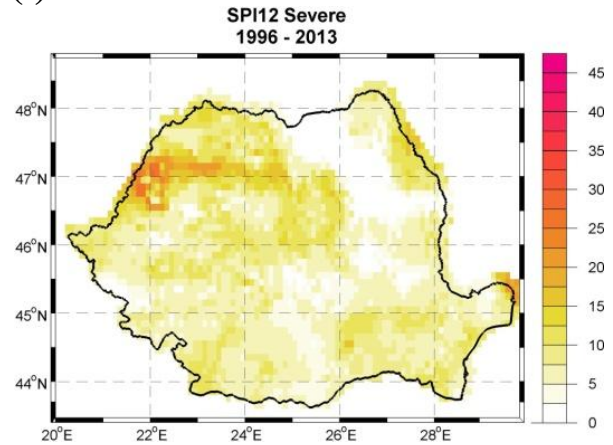

Figure 4. Total severe drought $(-2<\mathrm{SPI} \leq-1.5)$ duration maps over different periods of time [1962 - 1978 (first row), 1979 - 1995 (second row) and 1996 - 2013 (third row)] and for three different SPI times scales [SPI3 (first colum), SPI6 (second column) and SPI12 (third column)].

Units: number of months/period. 
(a)

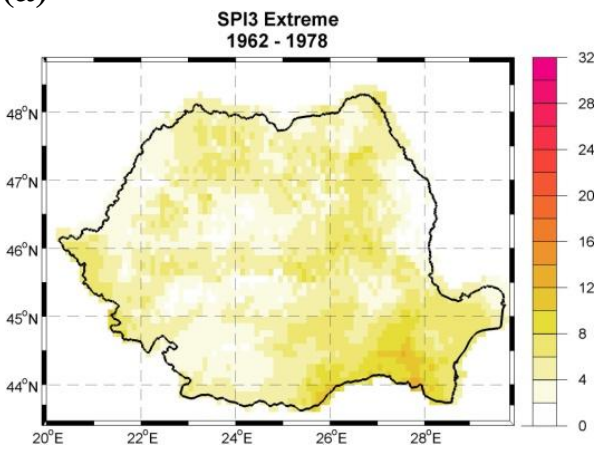

(d)

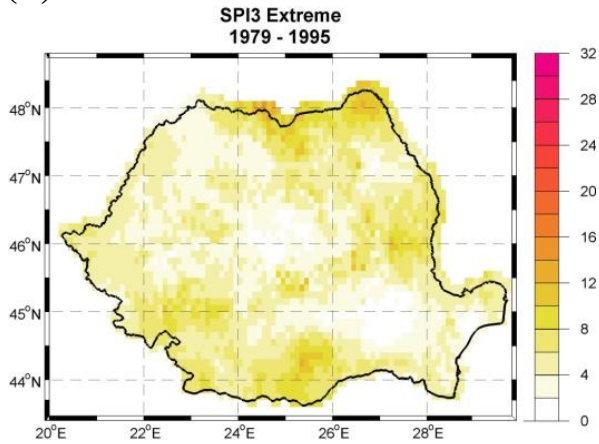

(g)

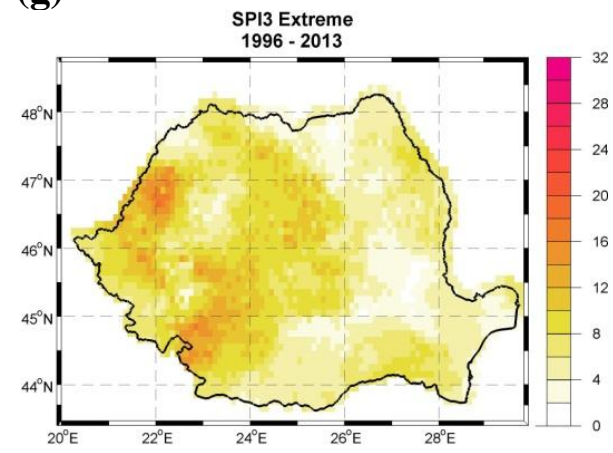

(b)

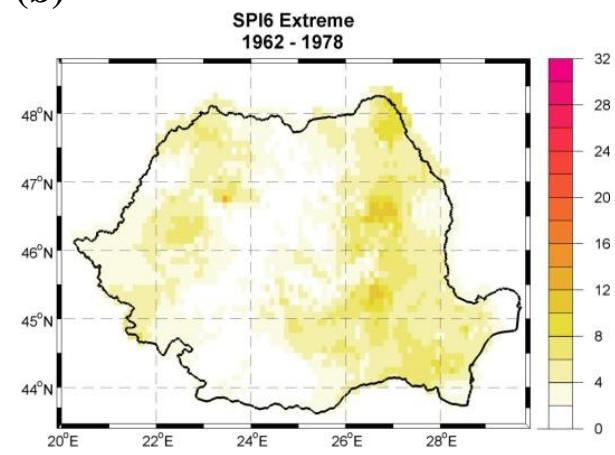

(e)

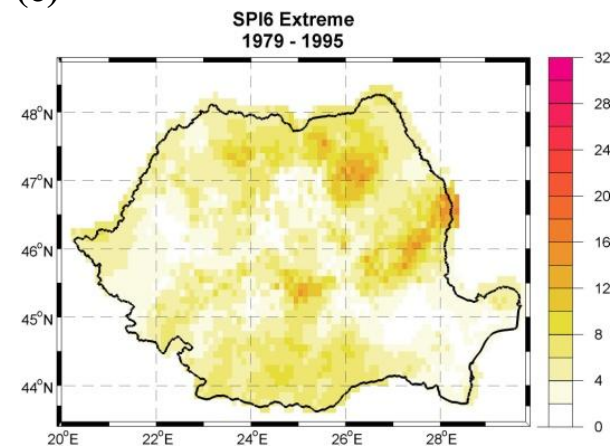

(h)

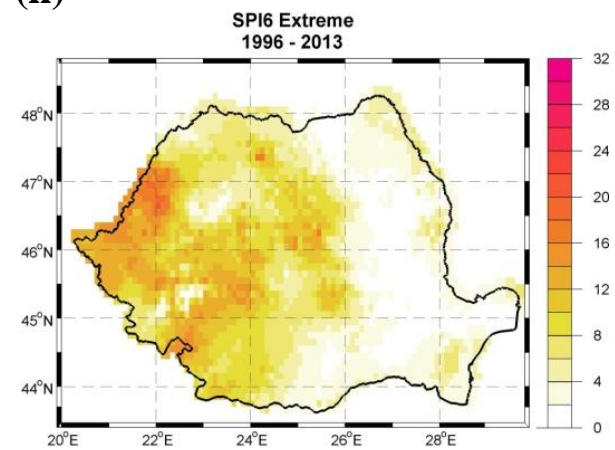

(c)

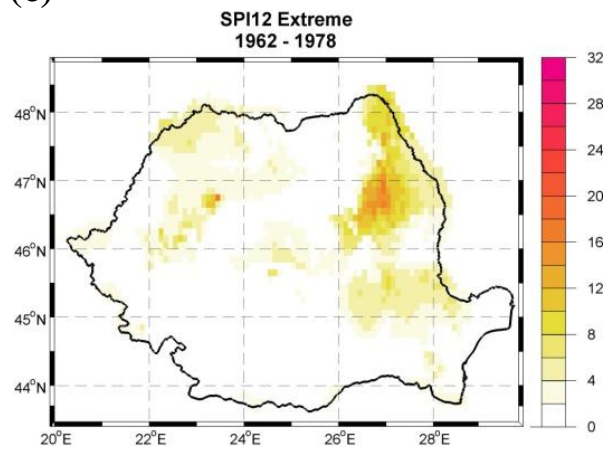

(f)

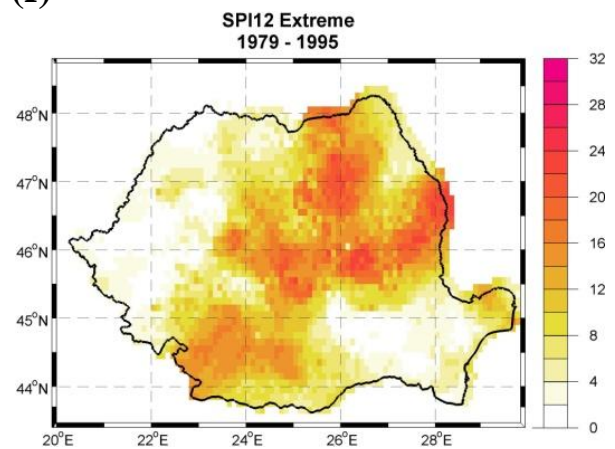

(i)

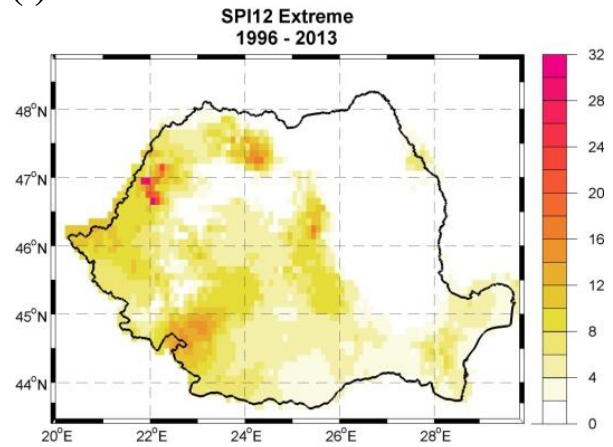

Figure 5. Total extreme drought (SPI $\leq-2)$ duration maps over different periods of time [1962 - 1978 (first row), 1979 - 1995 (second row) and 1996 - 2013 (third row)] and for three different SPI times scales [SPI3 (first colum), SPI6 (second column) and SPI12 (third column)].

Units: number of months/period. 


\section{Drought Romania}
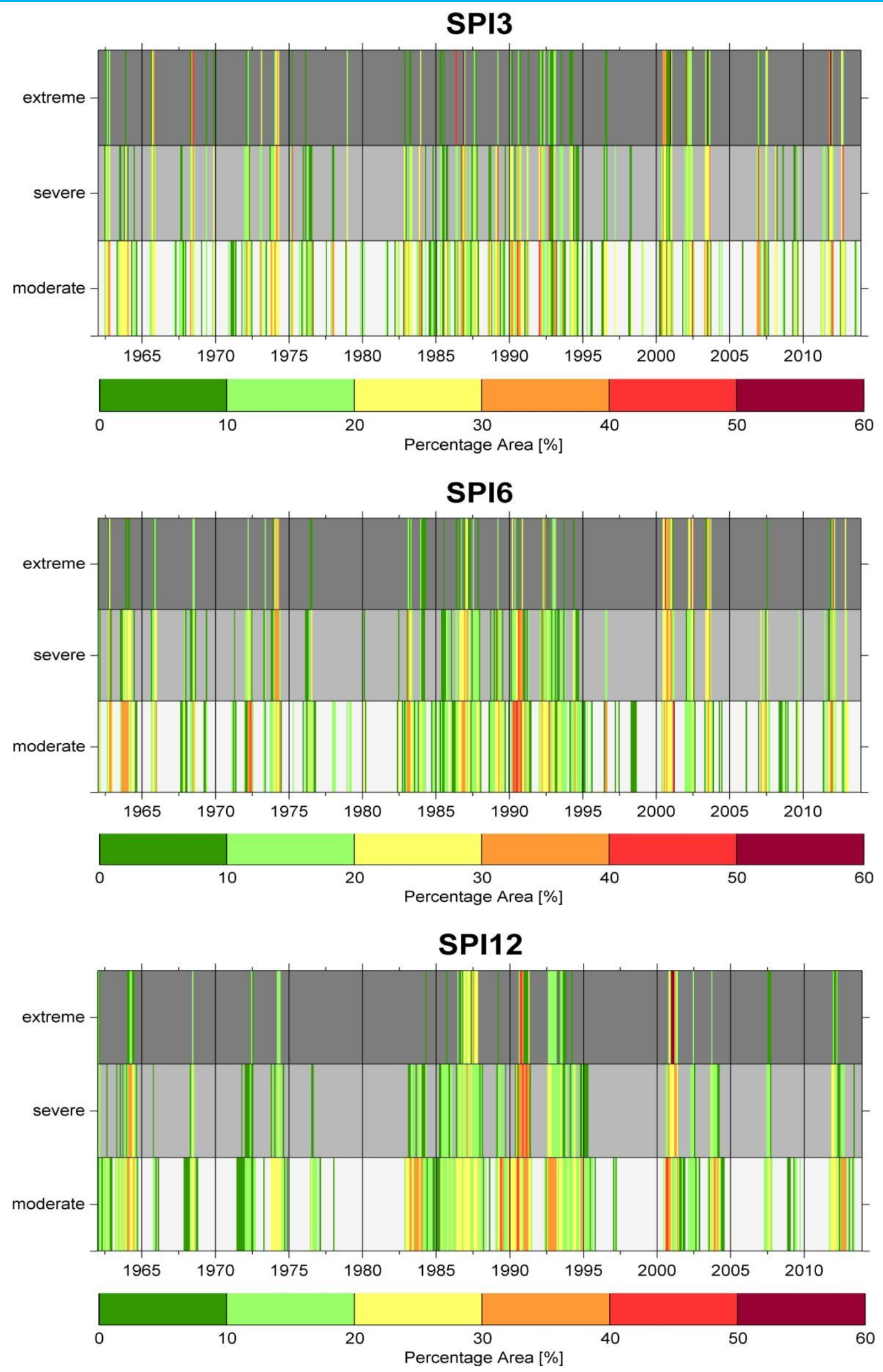

Figure 6. Temporal evolution of the percentage area of Romania territory affected by droughts at (a) 3-month, (b) 6-month and (c) 12-month time scales for three drought severity categories: moderate (light grey), severe (grey) and extreme (dark grey). 


\section{Drought Romania}

(a)

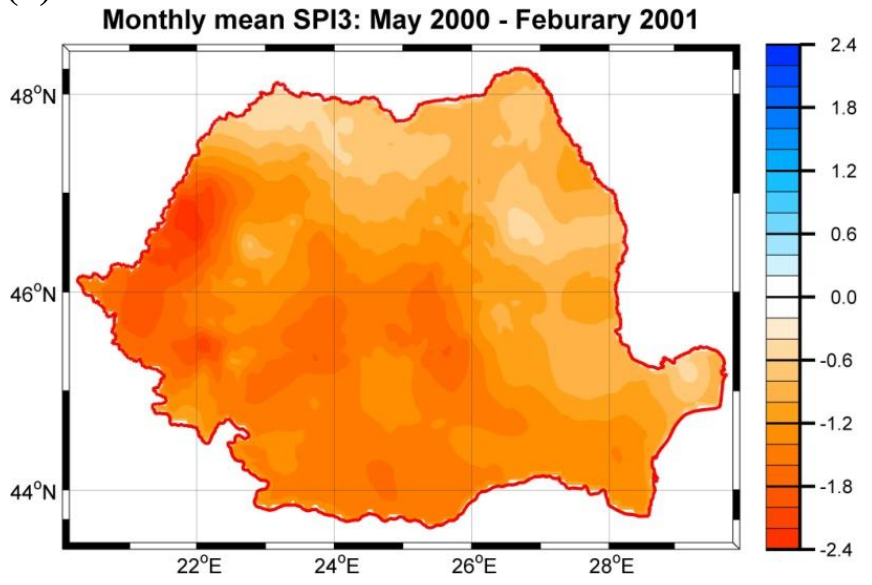

(b)

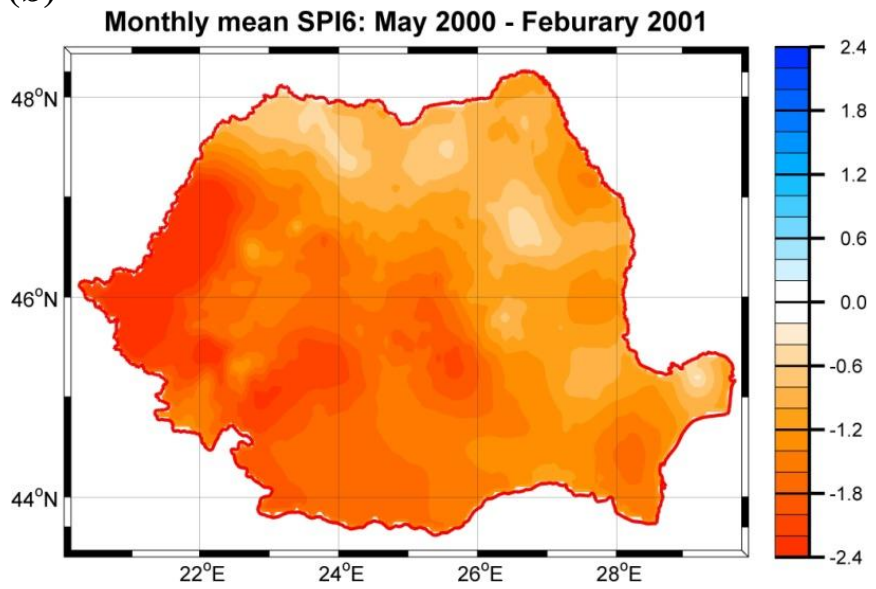

(c)

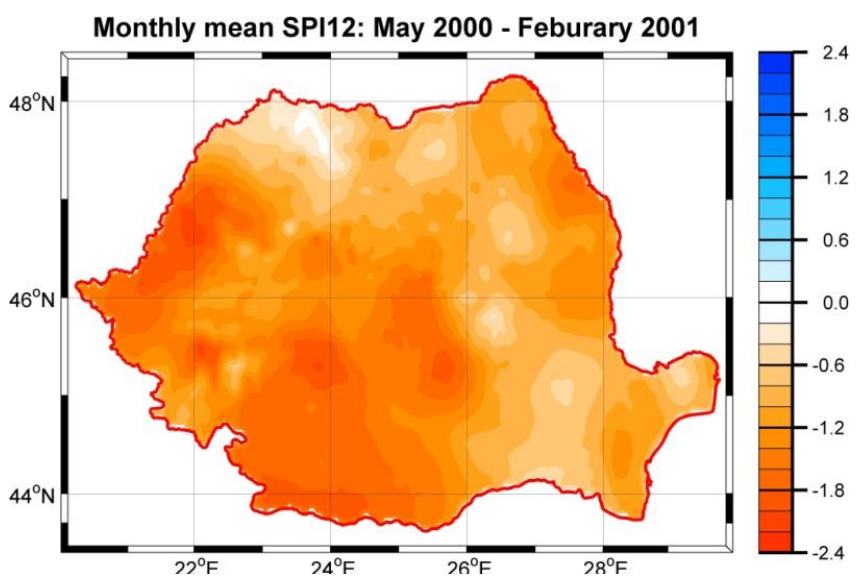

Figure 7. The spatial extent of the drought conditions at country level for the period May 2000 - February 2001:

(a) SPI3, (b) SPI6 and (c) SPI12. 
(a)

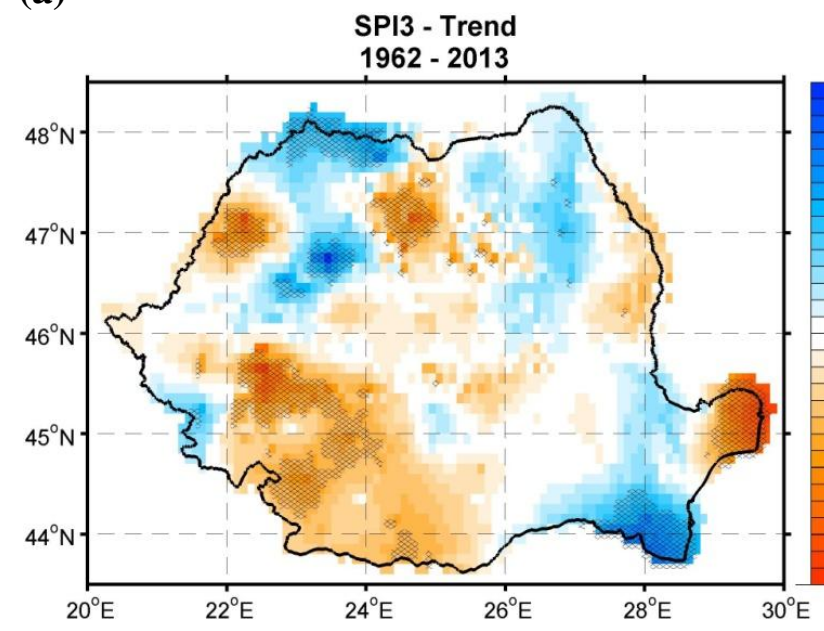

(b)

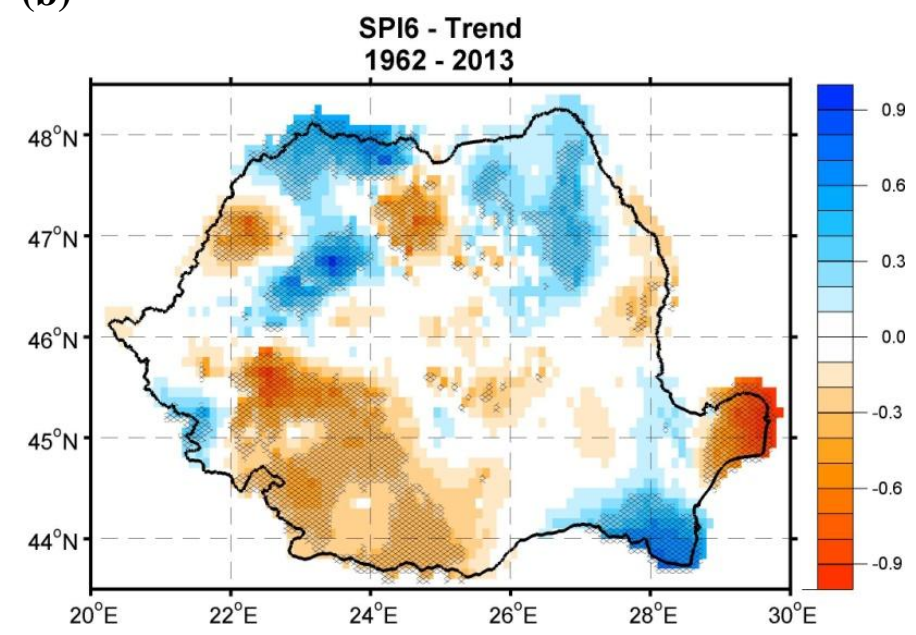

(c)

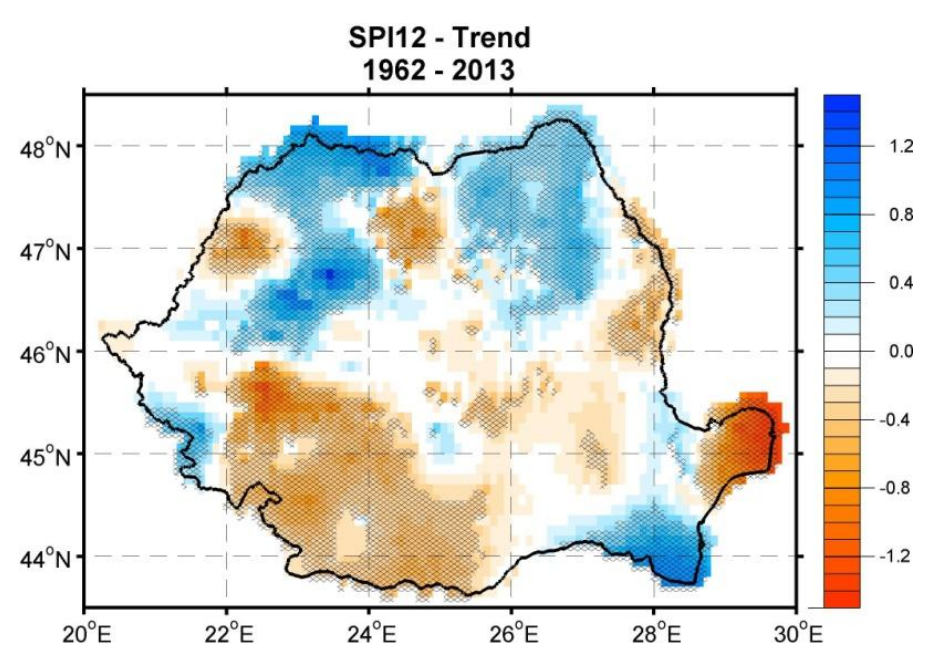

(d)

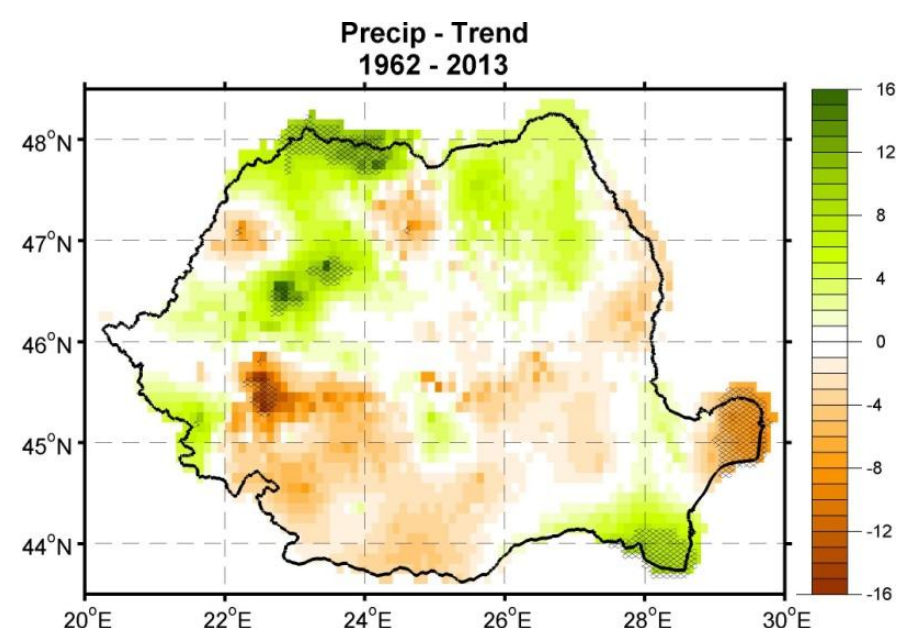

Figure 8. Trends (values/ 1962 - 2013 period) for the (a) SPI3, (b) SPI6, (c) SPI12 and (d) monthly precipitation totals.

The corresponding statistically significant linear trends at the 95 confindence level are shown attached.

For (a), (b) and (c) red (blue) indicates a linear trend towards more drier (wetter) conditions.

For (d) orange (green) indicates a linear trend towards more drier (wetter) conditions. 